\title{
Intelligent Software for Classification of Regional Inequality in Banten Province Using the Williamson Index
}

\author{
Perangkat Lunak Cerdas Untuk Klasifikasi Tingkat Ketimpangan Wilayah \\ Pada Provinsi Banten Menggunakan Indeks Williamson
}

Tubagus Rachmat Hidayat

TEBE121192@GMAIL.COM

Informatic Dept.

Faculty of Information Technology

Universitas Serang Raya

Banten, INDONESIA

\section{Harsiti}

HARSITI@YAHOO.COM

Information System Dept.

Faculty of Information Technology

Universitas Serang Raya

Banten, INDONESIA

\section{Zaenal Muttaqin}

Information System Dept.

Faculty of Information Technology

Universitas Serang Raya

Banten, INDONESIA

\author{
Maya Selvia Lauryn \\ Informatic Dept. \\ Faculty of Information Technology \\ Universitas Serang Raya \\ Banten, INDONESIA
}

Corresponding Autor: Zaenal Muttaqin

\begin{abstract}
The process of development in some areas occur quickly, but several areas experienced a very slow process. In this case, the local government has some problems in the process of implementing of local development, whether in policy making or proposing a strategy for local development, as well as improving the environment in order to support the development of their region's economy. Banten Province is a province located at the west of Java. The administrative conditions which is directly bordered with Jakarta as a capital city and West Java province makes Banten province become the most strategic regions. Based on economic growth data of Banten Province in 2010 - 2015, it can be seen that economic growth of Banten Province is increasing positively in five years. Although the growth of economic development in Banten province tend to be positive, it can be seen significantly that there is still a level of development that has an index of inequality in some districts or cites in Banten. In the process of identification the inequality level among the districts in
\end{abstract}


Banten province, the government usually analyze the case by using manual calculations to determine the policy that should be taken in addressing the inequality that occur in those districts. This process takes quite a long time to take the policy in structuring regional areas. In determining the area of inequality, the government requires Gross Regional Domestic Product (GRDP) data and the data of the population which can be calculated by using several inequality area methods. The method that often used is the Shift Share, Index Gain, Williamson Index and Klassen Typology. In some cases, Williamson index is often used in calculating the inequality between regions or territories. Several studies that had used Williamason index in identifying inequality development usually used the data analysis without particular tools such as software. It complicates the process of inequality analysis if the amount of the data is quite big. Therefore, this study aims to develop the software as a supporting tool for the identification of inequality development using Williamson index. The application is based-website to make it easier for the identification process.

Keywords: Williamson Index, Intelligent Applications, Artificial Intelligence, GRDP

\begin{abstract}
ABSTRAKSI
Proses pembangunan di beberapa daerah terjadi sangat cepat, namun beberapa daerah lainnya mengalami proses yang sangat lambat. Dalam hal ini pemerintah daerah memiliki beberapa permasalahan dalam penyelenggaraan proses pembangunan daerahnya, baik itu berupa pengambilan kebijakan atau dalam hal mengusulkan strategi pembangunan daerah, serta memperbaiki lingkungan didaerahnya agar mampu mendukung perkembangan perekonomian. Provinsi Banten merupakan provinsi yang terletak paling barat Pulau Jawa. Kondisi administratif yang langsung Berbatasan dengan ibukota negara DKI Jakarta dan Provinsi Jawa Barat membuat Provinsi Banten menjadi daerah paling strategis. Pada data pertumbuhan ekonomi Provinsi Banten pada tahun 2010 - 2015, dapat terlihat bahwa pertumbuhan ekonomi Provinsi Banten mengalami peningkatan yang positif dalam kurun waktu lima tahun. Meskipun pertumbuhan pembangunan ekonomi di Provinsi Banten cenderung positif, namun pada beberapa Kabupaten atau Kota di Provinsi Banten masih memiliki tingkat pembangunan yang memiliki indeks ketimpangan yang cukup signifikan. Dalam proses identifikasi ketimpangan wilayah di Provinsi Banten, biasanya pemerintah menganalisis kasus tersebut dengan cara perhitungan manual untuk menentukan kebijakan yang akan diambil dalam mengatasi ketimpangan yang terjadi pada wilayah tersebut. Proses ini cukup memakan waktu lama untuk mengambil kebijakan dalam penataan wilayah daerah. Dalam menentukan wilayah ketimpangan, pemerintah memerlukan data Produk Domestik Regional Bruto (PDRB) dan data jumlah populasi wilayah yang dapat dihitung menggunakan beberapa metode ketimpangan wilayah. Metode yang sering digunakan adalah Shift Share, Indeks Gain, Indeks Williamson dan Tipologi Klassen. Indeks Williamson sering digunakan dalam menghitung ketimpangan antara daerah atau wilayah. Beberapa penelitian yang menggunakan Indeks Williamason dalam mengidentifikasi ketimpangan pembangunan sebelumnya menggunakan analisis data tanpa alat bantu khusus seperti perangkat lunak. Hal tersebut menyulitkan proses analisis ketimpangan jika dihadapkan pada data dengan jumlah yang banyak. Oleh karena itu, penelitian ini bertujuan untuk mengembangkan perangkat lunak sebagai alat bantu identifikasi ketimpangan pembangunan menggunakan Indeks Williamson. Aplikasi dikembangkan berbasis web, sehingga lebih memudahkan proses identifikasi..
\end{abstract}

Keywords: Indeks Williamson, Aplikasi Cerdas, Kecerdasan Buatan, PDRB

\title{
1 Pendahuluan
}

Pembangunan dibeberapa daerah mengalami pertumbuhan yang sangat cepat namun beberapa daerah lainnya sangat lambat. Pemerintah dalam hal ini daerah memiliki beberapa permasalahan dalam penyelenggaraan proses pembangunan daerahnya, baik itu berupa pengambilan kebijakan atau mengusulkan strategi pembangunan daerahnya, dan memperbaiki lingkungan didaerahnya agar mampu mendukung perkembangan perekonomian.

Provinsi Banten merupakan provinsi yang terletak paling barat Pulau Jawa. Berbatasan dengan ibukota negara DKI Jakarta dan Provinsi Jawa Barat membuat Provinsi Banten menjadi daerah paling strategis. Provinsi Banten merupakan bentukan provinsi baru hasil pemekaran Provinsi Jawa Barat pada tahun 2000 dengan dikeluarkannya Undang-undang Republik Indonesia Nomor 23 Tahun 2000 dan menjadi provinsi ke-28 di Negara Kesatuan Republik Indonesia (NKRI). Dengan keunggulan strategis dari sisi lokasi, membuat perekonomian Banten bergerak cepat dan tumbuh dari tahun ke tahun. Data pertumbuhan ekonomi Provinsi Banten pada tahun 2010 - 2015, dapat terlihat bahwa pertumbuhan ekonomi Provinsi Banten mengalami peningkatan dalam kurun waktu lima tahun yang positif. Dari tahun 2011 mencapai 
17,62\%, tahun 2012 mencapai 18,82\%, tahun 2013 mencapai 20,08\% dan sampai dengan 2015 mencapai $22,31 \%$ yang cukup meningkat tiap tahunnya (BPS, 2015).

Provinsi Banten memiliki 8 daerah administrasi yaitu terdiri dari 4 kabupaten dan 4 kota dan Kota Serang dipilih sebagai ibukota provinsi. Empat kabupaten yang dimaksud adalah Tangerang, Serang, Pandeglang dan Lebak, sedangkan empat kota tersebut adalah Tangerang Kota, Serang, Cilegon dan Kota Tangerang Selatan.

Meskipun pertumbuhan pembangunan ekonomi di Provinsi Banten cenderung positif namun beberapa Kabupaten atau Kota di Provinsi Banten masih memiliki tingkat pembangunan yang memiliki indeks ketimpangan yang cukup signifikan. Diantaranya adalah Kabupaten Pandeglang dan Lebak (Munandar dan Winarko, 2015). Proses identifikasi ketimpangan wilayah di Provinsi Banten, biasanya pemerintah menganalisis dengan cara perhitungan manual untuk menentukan kebijakan dalam ketimpangan wilayah tersebut. Yang dimana cukup memakan waktu lama untuk mengambil kebijakan dalam penataan wilayah daerah.

Menentukan wilayah ketimpangan, pemerintah memerlukan data PDRB dan data jumlah populasi wilayah yang dapat dihitung menggunakan beberapa metode ketimpangan wilayah. Metode yang sering digunakan adalah Shift Share, Indeks Gain, Indeks Williamson dan Tipologi Klassen. Indeks Williamson sering digunakan dalam menghitung ketimpangan antara daerah atau wilayah (Sudarlan dkk, 2015; Rukmana, 2012; Masnawi dkk, 2015). Beberapa penelitian yang menggunakan Indeks Williamason dalam mengidentifikasi ketimpangan pembangunan sebelumnya menggunakan analisis data tanpa alat bantu khusus seperti perangkat lunak. Sehingga menyulitkan analisis ketimpangan jika dihadapkan pada data dengan jumlah yang banyak. Oleh karena itu, penelitian ini bertujuan untuk mengembangkan perangkat lunak sebagai alat bantu identifikasi ketimpangan pembangunan menggunakan Indeks Williamson. Aplikasi dikembangkan berbasis web, sehingga lebih memudahkan.

\section{Tinjauan Pustaka}

Beberapa penelitian sebelumnya mengidentifikasi ketimpangan pembangunan menggunakan Indeks Williamson sudah banyak dilakukan antara lain, identifikasi ketimpangan wilayah antar kecamatan di Kabupaten Buleleng tahun 2007-2011 yang bertujuan untuk mengetahui pola pertumbuhan ekonomi perkecamatan di Kabupaten Buleleng (Sari dan Budhi, 2013; Cahyo dan Wijaya, 2014; Raswita dan Utama, 2013; Zakaria, 2013), uji perbedaan pembangunan ekonomi antara di daerah Sumatera Selatan (Panorama, 2013).

Teknik lainnya yang digunakan untuk menganalisis hubungan antara tingkat disparitas pembangunan ekonomi dilakukan di kabupaten dan kota di Provinsi Sulawesi Selatan. Menggunakan Tipologi Klassen dan Indeks Williamson digunakan untuk memetakan tingkat pertumbuhan ekonomi dan tingkat disparitas pendapatan selama kurun waktu 2005-2010. Hasil menunjukan bahwa pembangunan ekonomi di Kota Parepare dan Palopo dan Kabupaten Luwu Utara secara pendapatan yang lebih merata. Sedangkan daerah lainnya tidak mampu mencapai dua indikator pembangunan daerah tersebut pada saat yang bersamaan termasuk didalamnya kota Makassar yang relatif sudah lebih maju (Razak, 2011; Sokolowicz, 2015; Suwandi, 2015; Hidayat, 2014).

Beberapa metode lain yang sering digunakan adalah Shift Share, Indeks Gain, Indeks Williamson dan Tipologi Klassen (Munandar dan Winarko, 2015). Dan Indeks Williamson sering digunakan dalam menghitung kesenjangan antara daerah atau wilayah (Sudarlan dkk, 2015; Rukmana, 2012; Masnawi dkk, 2015). Indeks Williamson dapat digunakan untuk indentifikasi suatu ketimpangan dalam sebuah wilayah agar dapat mengambil sebuah kebijakan untuk kemajuan wilayah daerah (Sutrisno, 2012; Woods dan Lecturer, 2007; Yeniwati, 2013).

Dari beberapa penelitian diatas, metode Indeks Williamson dapat digunakan untuk mengidentifikasi sebuah ketimpangan wilayah diberbagai wilayah Indonesia termasuk diwilayah Provinsi Banten. Namun analisis yang dilakukan belum menggunakan alat bantu perangkat lunak, untuk itu penelitian ingin mengimplementasikan Indeks Williamson kedalam bentuk aplikasi cerdas yang dapat membantu pemerintah daerah dalam mengambil kesimpulan atau kebijakan untuk mengidentifikasi ketimpangan wilayah di Provinsi Banten.

\section{Ketimpangan Pembangunan}

Ketimpangan pembangunan antar daerah dengan pusat dan antar daerah satu dengan daerah lain merupakan suatu hal yang wajar, karena adanya perbedaan dalam sumber daya dan awal pelaksanaan 
pembangunan antar daerah menurut Williamson (1965) dalam Hartono (2008). Ketimpangan yang paling lazim dibicarakan adalah ketimpangan ekonomi. Dalam ketimpangan ada ketimpangan pembangunan ekonomi antar daerah secara absolut maupun ketimpangan relatif antara potensi dan tingkat kesejahteraan tersebut dapat menimbulkan masalah dalam hubungan antar daerah (Hartono, 2008).

\section{Metode Indeks Williamson}

Indeks Williamson digunakan dalam mengukur ketimpangan pendapatan antar wilayah. Rumus indeks Williamson ini akan menghasilkan angka indeks yang lebih besar dan sama dengan 0 (nol) dan lebih dari 1 (satu). Secara ekstrim, jika angka indeks sama 0 (nol) maka menandakan tidak terjadi ketimpangan ekonomi. Sebaliknya, angka indeks yang lebih besar dari nol menunjukan adanya ketimpangan. Semakin besar indeksnya berarti semakin besar pula tingkat ketimpangan ekonominya (Sutarno dan Kuncoro, 2003). Rumus dari Indeks Williamson adalah sebagai berikut:

$$
C V w=\frac{\sqrt{\sum(Y i-\bar{y})^{2} f i / n}}{\bar{y}}
$$

Keterangan :

$\begin{array}{ll}\mathrm{CVw} & =\text { Indeks Williamson } \\ \mathrm{fi} & =\text { Jumlah penduduk kabupaten/kota (jiwa) } \\ \mathrm{n} & =\text { Jumlah penduduk Provinsi (jiwa) } \\ \mathrm{Yi} & =\text { PDRB per kapita kabupaten/kota (Rupiah) } \\ \mathrm{y} & =\text { PDRB per kapita rata-rata Provinsi (Rupiah) }\end{array}$

\section{Metodologi Penelitian}

Metodologi yang digunakan dalam penelitian ini adalah studi pustaka yaitu mengumpulkan informasi baik dari buku atau jurnal yang berkaitan dengan judul tersebut. Dalam suatu penelitian, metode yang digunakan akan memegang peranan penting karena menentukan keberhasilan suatu penelitian, dalam hal ini dipergunakan untuk menghimpun data yang diperlukan. Jadi secara umum metode penelitian adalah metode yang digunakan untuk mengumpulkan dan menganalisis data mengenai suatu masalah. Secara umum tahapan-tahapan pada penelitian ini dimulai dengan tahap studi literatur dimana tahap ini melakukan pembelajaran dan penggalian tetang konsep penelitian melalui studi pustaka atau jurnal penelitianpenelitian yang telah dilakukan sebelumnya untuk dijadikan kajian. Tahap berikutnya adalah pengumpulan dan Pengklasifikasi Data. Tahap ini melakukan pengumpulan data yang berhubungan dengan hal ketimpangan yang ada di Provinsi Banten dan mengolah data mentah yang telah dikumpulkan, agar bisa dianalisa berdasarkan metode Indeks Williamson yang peneliti ambil sebagai metode penelitian. Selanjutnya dilakukan perancangan Aplikasi PIK (Program Identifikasi Ketimpangan). Pada tahap ini dibuat perancangan dan mendesign sistem kemudian dilakukan pengkodean kedalam pemrograman berasis web. Tahap terakhir adalah pengujian sistem untuk mengetahui apakah program yang dihasilkan bisa berjalan sesuai perancangan.

\section{Hasil dan Pembahasan}

\subsection{Arsitektur Aplikasi PIK (Program Identifikasi Ketimpangan)}

Perancangan arsitektur Aplikasi PIK ini terdiri dari pengguna yang menggunakan fasilitas internet sebagai media browser, web server sebagai media penyedia layanan modul php, dan database, yang saling terhubung. Sebagai simulasi karena tidak menggunakan jaringan internet, maka menggunakan personal server mempunya web server yang berjalan di internet dan admin yang melakukan update data. Gambar arsitektur aplikasi dapat dilihat pada Gambar 1. 


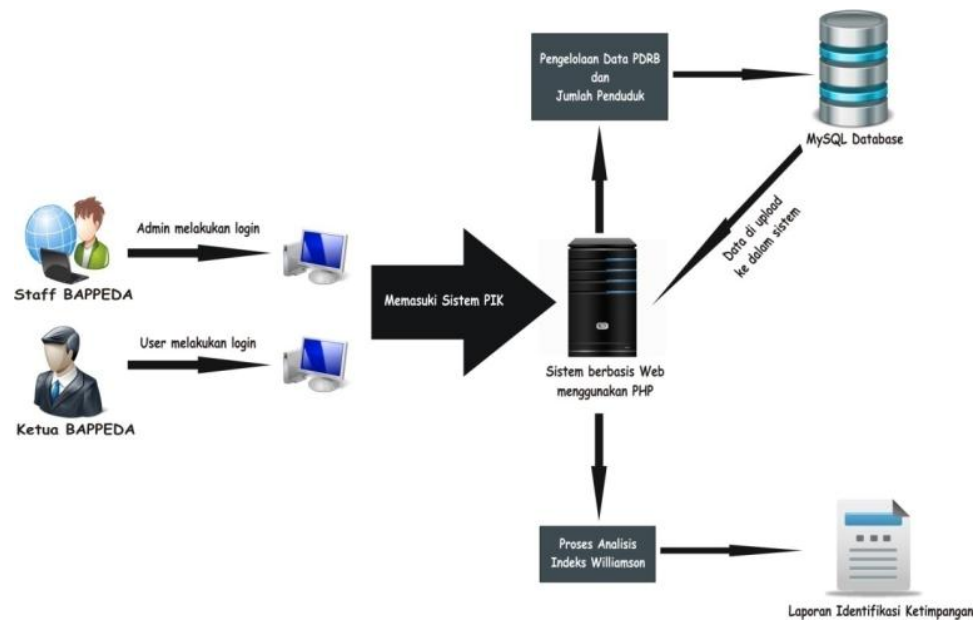

Gambar 1. Arsitektur Aplikasi PIK

\subsection{Analisis Ketimpangan Pembangunan Menggunakan Index Williamson}

Perhitungan Indeks Williamson pada penelitian ini menggunakan data PDRB dan jumlah populasi pada tahun 2012, seperti diperlihatkan pada Tabel 1.

Tabel 1. Perhitungan Indeks Williamson

\begin{tabular}{|c|c|c|c|c|c|c|c|}
\hline $\begin{array}{c}\text { Kabupaten/ } \\
\text { Kota }\end{array}$ & $\begin{array}{c}\text { PDRB } \\
\text { Perkapita (Yi) } \\
\end{array}$ & $\begin{array}{c}\text { Penduduk } \\
\text { (fi) }\end{array}$ & $Y i-y$ & $(Y i-y)^{2}$ & $f i / n$ & $\begin{array}{c}(Y i-y)^{2} \\
f i / n \\
\end{array}$ & CVw \\
\hline Kab Lebak & 11,30 & 1.239 .660 & $-9,99$ & 99,83 & 0,11 & 11,00 & 0,16 \\
\hline Kab Pandeglang & 4,07 & 1.181 .430 & $-17,22$ & 296,45 & 0,11 & 31,13 & 0,26 \\
\hline Kab Serang & 13,46 & 1.448 .964 & $-7,83$ & 61,31 & 0,13 & 7,90 & 0,13 \\
\hline Kab Tangerang & 20,47 & 3.050 .929 & $-0,82$ & 0,66 & 0,27 & 0,18 & 0,02 \\
\hline Kota Cilegon & 49,63 & 392.341 & 28,34 & 802,95 & 0,03 & 28,01 & 0,25 \\
\hline Kota Serang & 5,60 & 611.897 & $-15,69$ & 246,29 & 0,05 & 13,40 & 0,17 \\
\hline Kota Tangerang & 40,11 & 1.918 .556 & 18,82 & 354,05 & 0,17 & 60,39 & 0,36 \\
\hline $\begin{array}{l}\text { Kota Tangerang } \\
\text { Selatan }\end{array}$ & 25,69 & 1.405 .170 & 4,40 & 19,32 & 0,12 & 2,41 & 0,07 \\
\hline $\begin{array}{l}\text { Rata-rata } \\
\text { Perkapita }\end{array}$ & 21,29 & 11.248.947 & & & Total & 154,41 & 0,58 \\
\hline
\end{tabular}

1) Menentukan PDRB perkapita ( $Y i$ )

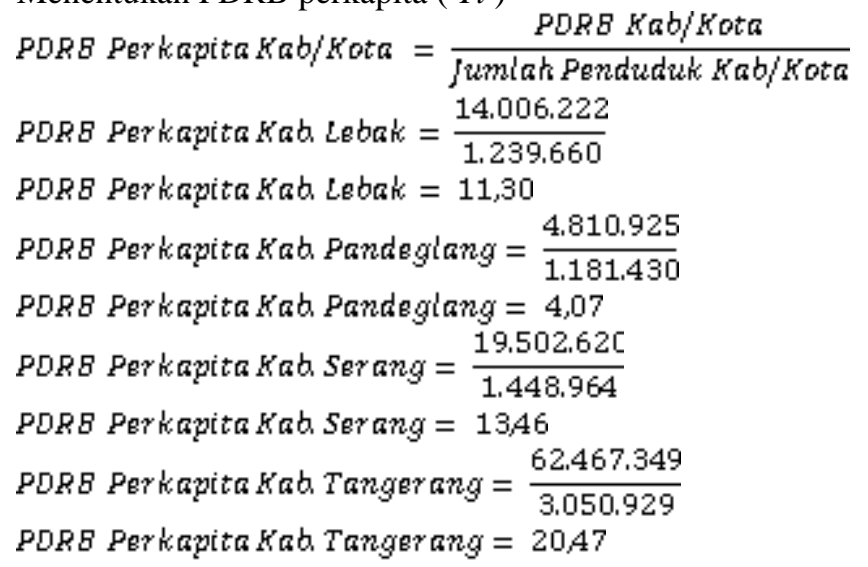




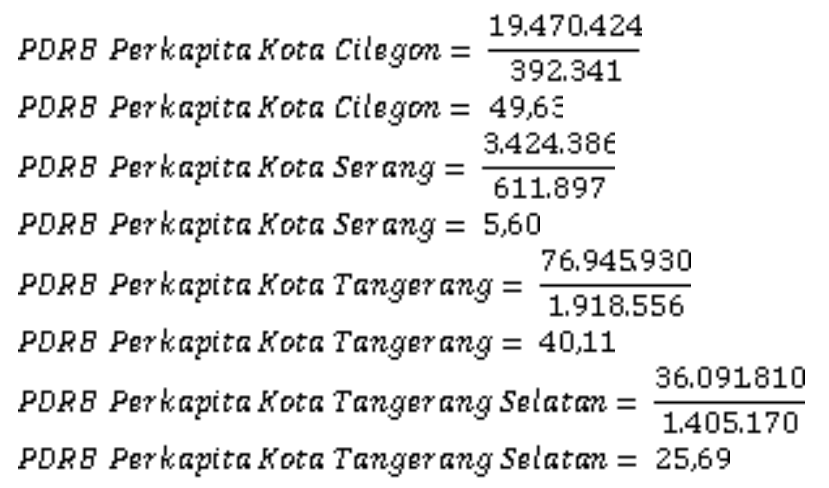

2) Menentukan rata-rata perkapita $(\bar{y})$

Rata - rata Perkapita $=\frac{\sum \text { PORB Perkapita Provinsi }}{n}$

Ket $: \mathrm{n}=$ Jumlah banyaknya wilayah kabupaten $/$ kota

$$
\begin{aligned}
& \text { Rata - rata Perkapita Proy. Banten }= \begin{array}{c}
11,30+4,07+13,46+20,47 \\
+49,63+5,60+40,11+25,69
\end{array} \\
& \text { Rata - rata Perkapita Prov. Banten }=\frac{170,32}{8} \\
& \text { Rata - rata Perkapita Prov. Banten }=21,29
\end{aligned}
$$

3) Mencari nilai $Y i-y$ dengan perhitungan sebagai berikut :

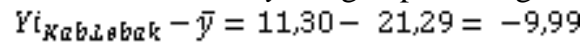

$Y i_{K a b] a+1] g[a+1 g}-\bar{y}=4,07-21,29=-17,22$

$Y i_{\text {Kabsarang }}-\bar{y}=13,46-21,29=-7,83$

$Y i_{\text {Kabitang aratg }}-\bar{y}=20,47-21,29=-0,82$

$Y i_{\text {Kota Cilegot }}-\bar{y}=49,63-21,29=28,34$

$Y i_{\text {Kota sarang }}-\bar{y}=5,60-21,29=-15,69$

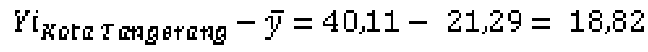

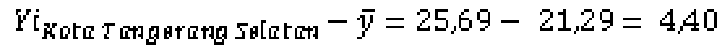

4) Setelah mencari nilai $Y i-y$, hasil tersebut dikuadratkan dengan perhitungan sebagai berikut :

$$
\begin{aligned}
& \left(\mathrm{Yi}_{\mathrm{K}_{\mathrm{ab} \text { abak }}}-\bar{y}\right)^{2}=(-9,99)^{2}=99,83 \\
& \left(\mathrm{Yi}_{\text {Kab?a+1deglang }}-\bar{y}\right)^{2}=(-17,22)^{2}=296,45 \\
& \left(Y i_{\text {Kabsaratag }}-\bar{y}\right)^{2}=(-7,83)^{2}=61,31 \\
& \left(Y i_{\text {Kabiangerang }}-\bar{y}\right)^{2}=(-0,82)^{2}=0,66 \\
& \left(\mathrm{Yi}_{\text {Kota tilegot }}-\bar{y}\right)^{2}=(28,34)^{2}=802,95 \\
& \left(Y_{\text {Kota serang }}-\bar{y}\right)^{2}=(-15,69)^{2}=246,29 \\
& \left(Y i_{\text {Kota } \tau_{\text {ang }}}-\bar{y}\right)^{2}=(18,82)^{2}=354,05
\end{aligned}
$$

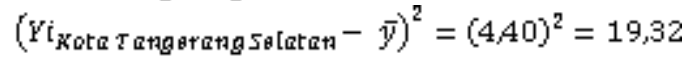

5) Mencari nilai $\mathrm{fi} / \mathrm{n}$ dengan perhitungan sebagai berikut :

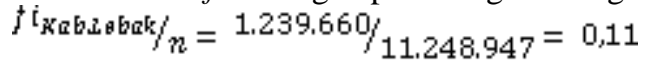

$$
\begin{aligned}
& f i_{\text {Ka Bandeg[atag }} /_{n}=1.181 .430 / 11.248 .947=0,11 \\
& f i_{\text {Ka }} \text { sarang }_{n}=1.448 .964 / 11.248 .947=0,13 \\
& f i_{\text {Kab.tangeratag }} /_{n}=3.050 .929 / 11.248 .947=0,27
\end{aligned}
$$


$f i_{\text {Kota tilegort/ } / n}=392.341 / 11.248 .947=0,03$

$f i_{\text {Kota Sarang }} /_{n}=611.897 / 11.248947=0,05$

$f i_{\text {Kota }} \tau_{\text {angarang }} / n=1.918 .556 / 11.248 .947=0,17$

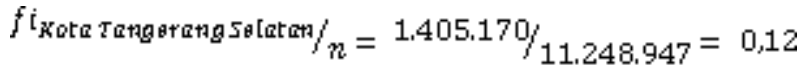

6) Mencari nilai $(Y i-y)^{2} f i / n$ dengan perhitungan sebagai berikut :

$$
\begin{aligned}
& \left\{(Y i-\bar{y})^{2 f i} / n\right\}_{\text {Kabjabak }}=99,83 \times 0,11=11,00
\end{aligned}
$$

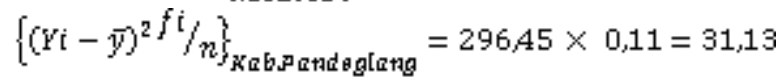

$$
\begin{aligned}
& \left\{(Y i-\bar{y})^{2 f i} / n\right\}_{\text {Kabsarang }}=61,31 \times 0,13=7,90 \\
& \left\{(Y i-\bar{y})^{2 f i} / n\right\}_{\text {Kab.tanger ang }}=0,66 \times 0,27=0,18 \\
& \left\{(\mathrm{Yi}-\bar{y})^{2 f i} / n\right\}_{\text {Kota tilegor }}=802,95 \times 0,03=28,01 \\
& \left\{(\mathrm{Yi}-\bar{y})^{2 f i} / n\right\}_{\text {Kota Sar ang }}=246,29 \times 0,05=13,40 \\
& \left\{(Y i-\bar{y})^{2 f i} / n\right\}_{\text {Kota } \tau_{\text {anger ang }}}=354,05 \times 0,17=60,39 \\
& \left\{(Y i-\bar{y})^{2 f i} / n\right\}_{\text {Kota } \tau_{\text {anger ang so[atart }}}=19,32 \times 0,12=2,41
\end{aligned}
$$

7) Setelah mencari nilai $(Y i-y)^{2} f i / n$, hasil tersebut dijumlahkan dengan perhitungan sebagai berikut :

$\sum(\mathrm{Yi}-\bar{y})^{2}+i / n=11,00+31,13+7,90+0,18+28,01+13,40+60,39+2,41=154,41$

8) Setelah dijumlahkan, langkah selanjutnya mencari nilai Indeks Williamson setiap wilayah Kab/Kota dengan rumus sebagai berikut :

$$
\begin{aligned}
& C V w=\frac{\sqrt{\sum(Y i-\bar{y})^{2} f i / n}}{\bar{y}} \\
& C V W_{\text {Kabjabak }}=\frac{\sqrt{11,00}}{21,29} \\
& C V w_{K a b j \theta b a k}=\frac{3,32}{21,29} \\
& C V W_{\text {Kabjabak }}=0,16
\end{aligned}
$$

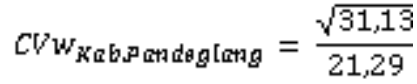

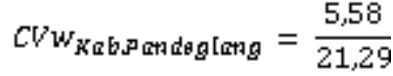

$$
\begin{aligned}
& C V W_{\text {Kab. and deglang }}=0,26 \\
& C V W_{\text {KabSer ath }}=\frac{\sqrt{7,90}}{21,29} \\
& C V W_{\text {KabS A ata }}=\frac{2,81}{21,29} \\
& C V W_{\text {Kabser ang }}=0,13 \\
& C V W_{K a b, \tau a \text { \#g aratg }}=\frac{\sqrt{0,18}}{21,29} \\
& C V w_{K a b, \tau a+g \text { arang }}=\frac{0,42}{21,29} \\
& C V W_{K a b . T_{a n g} \text { arang }}=0,02
\end{aligned}
$$




$$
\begin{aligned}
& C V w_{\text {Kota cilagot }}=\frac{\sqrt{28,01}}{21,29} \\
& \text { CVW } W_{\text {Kota cilegot }}=\frac{5,29}{21,29} \\
& C V w_{\text {Kota cilagot }}=0,25 \\
& C V W_{\text {Kota Sar ang }}=\frac{\sqrt{13,40}}{21,29} \\
& C V w_{\text {Kota ser ang }}=\frac{3,66}{21,29} \\
& C V W_{\text {Rota serang }}=0,17 \\
& C V W_{\text {Kota }} \text { angarang }=\frac{\sqrt{60,35}}{21,29}
\end{aligned}
$$

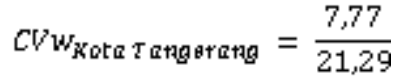

$$
\begin{aligned}
& C V w_{\text {Kota }} \tau_{\text {angatang }}=0,36 \\
& C V W_{\text {Kota }} \text { angatang } S_{\text {elatan }}=\frac{\sqrt{241}}{21,29} \\
& C V w_{\text {Kota }} \tau_{\text {angaratg Sa [atat }}=\frac{1,55}{21,29}
\end{aligned}
$$

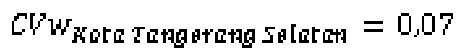

\begin{tabular}{|c|c|c|c|c|}
\hline No. & Kabupaten/Kota & $\begin{array}{l}\text { Nilai } \\
\text { CVw }\end{array}$ & $\begin{array}{c}\text { Status } \\
\text { Ketimpangan } \\
\end{array}$ & Rekomendasi \\
\hline 1. & KAB. LEBAK & 0,16 & $\begin{array}{l}\text { Kesenjangan level } \\
\text { rendah }\end{array}$ & $\begin{array}{l}\text { Bukan prioritas utama } \\
\text { pembangunan }\end{array}$ \\
\hline 2. & KAB. PANDEGLANG & 0,26 & $\begin{array}{l}\text { Kesenjangan level } \\
\text { rendah }\end{array}$ & $\begin{array}{l}\text { Bukan prioritas utama } \\
\text { pembangunan }\end{array}$ \\
\hline 3. & KAB. SERANG & 0,13 & $\begin{array}{l}\text { Kesenjangan level } \\
\text { rendah }\end{array}$ & $\begin{array}{l}\text { Bukan prioritas utama } \\
\text { pembangunan }\end{array}$ \\
\hline 4. & KAB. TANGERANG & 0,02 & $\begin{array}{l}\text { Kesenjangan level } \\
\text { rendah }\end{array}$ & $\begin{array}{l}\text { Bukan prioritas utama } \\
\text { pembangunan }\end{array}$ \\
\hline 5. & KOTA CILEGON & 0,25 & $\begin{array}{l}\text { Kesenjangan level } \\
\text { rendah }\end{array}$ & $\begin{array}{l}\text { Bukan prioritas utama } \\
\text { pembangunan }\end{array}$ \\
\hline 6. & KOTA SERANG & 0,17 & $\begin{array}{l}\text { Kesenjangan level } \\
\text { rendah }\end{array}$ & $\begin{array}{l}\text { Bukan prioritas utama } \\
\text { pembangunan }\end{array}$ \\
\hline
\end{tabular}

9) Setelah mengetahui Indeks Williamson setiap wilayah Kab/Kota, untuk langkah terakhir adalah mencari nilai Indeks Williamson Provinsi Banten dengan rumus sebagai berikut :

$$
\begin{aligned}
& C V w=\frac{\sqrt{\sum(\mathrm{Yi}-\bar{y})^{2} f \mathrm{i} / n}}{\bar{y}} \\
& C V W_{\text {Prov.Batate+1 }}=\frac{\sqrt{154,41}}{21,29} \\
& C V W_{P+O W B a+1+1}=\frac{12,43}{21,29} \\
& C V W_{P+C O B C+1+B+1}=0,58
\end{aligned}
$$

10) Melakukan pengujian aturan Indeks Williamson

Karena aturan indeks Williamson adalah $0,35 \leq \mathrm{CVw} \leq 0,5$, maka dari hasil perhitungan analisis diatas di daerah Kabupaten dan Kota pada Provinsi Banten pada tahun 2012 dengan hasil yang diperlihatkan pada Tabel 2.

Tabel 2. Hasil Analisis Indeks Williamson 
HidAYAT DKK, INTELLIGENT SOFTWARE FOR ClASSIFICATION OF REGIONAL INEQUALITY...

\begin{tabular}{|c|c|c|c|c|c|c|}
\hline 7. & KOTA TANGERANG & 0,36 & $\begin{array}{l}\text { Kesenjangan } \\
\text { menengah }\end{array}$ & level & $\begin{array}{l}\text { Prioritas } \\
\text { pembangunan } \\
\text { basis }\end{array}$ & $\begin{array}{l}\text { utama } \\
\text { sektor }\end{array}$ \\
\hline 8. & $\begin{array}{l}\text { KOTA } \\
\text { SELATAN }\end{array}$ & 0,07 & $\begin{array}{l}\text { Kesenjangan } \\
\text { rendah }\end{array}$ & level & $\begin{array}{l}\text { Bukan prioritas } \\
\text { pembangunan }\end{array}$ & utama \\
\hline
\end{tabular}

\section{Kesimpulan}

Hasil penelitian memperlihatkan bahwa dari delapan kota / kabupaten di Provinsi Banten hampir sebagian besar masuk ke dalam status ketimpangan level rendah. Artinya bahwa semua kabupaten / kota pada dasarnya sudah mengalami perkembangan pembangunan yang cukup signifikan.

\section{References}

Astamal.R., 2010. Modul Pemrograman PHP, LUG STIKOM Surabaya.

Cahyono.S.A dan Wijaya.W.W., 2014. Identifikasi Sektor Ekonomi Unggulan Dan Ketimpangan Pendapatan Antar Kabupaten Di Sub Das Bengawan Solo Hulu, JURNAL Penelitian Sosial dan Ekonomi Kehutanan Vol. 11 No. 1 , Hal. $32-43$.

Dahria.M., 2008. Kecerdasan Buatan (Artificial Intelligence), Jurnal SAINTIKOM Vol. 5, No.2.

Dhyatmika.K.T,. 2013. Analisis Ketimpangan Pembangunan Provinsi Banten Pasca Pemekaran, Semarang.

Dhyatmika.K.W dan Atmanti.H.D., 2013. Analisis Ketimpangan Pembangunan Provinsi Banten Pasca Pemekaran, Diponegoro Journal Of Economics Volume 2, Nomor 2, Halaman 1-8.

Hartono.B,. 2008. Analisis Ketimpangan Pembangunan Ekonomi Di Provinsi Jawa Tengah Analisis Ketimpangan Pembangunan Ekonomi Di Provinsi Jawa Tengah, Semarang.

Hidayat.M,. 2014. Inequality Across Districts and Cities In The Riau, Economic Journal Of Emerging Markets, 6(2), 106-118.

Masnawi.A dkk., 2015. Analysis Of Regional Growth And Development Disparaties In Mamuju Regensy, West Sulawesi, International Journal of Management Research and Busnies Strategy Vol. 4, No.3.

Muchtholifah,. 2010. Pengaruh Produk Domestik Regional (Pdrb), Inflasi, Investasi Industri Dan Jumlah Tenaga Kerja Terhadap Pendapatan Asli Daerah (Pad) Di Kota Mojokerto, Jurnal Ilmu Ekonomi Pembangunan Vol. 1, No.1.

Munandar, T.A dan Winarko. E,. 2015. Regional Development Classification Model Using Decision Tree Approach, International Journal of Computer Applications (0975 - 8887) Volume 114 - No. 8.

Panorama.M., 2013. Disparaties in Economic Development, International Conference on the Modern Development of Humanities and Social Science (MDHSS 2013).

Praduwiratna.R., 2010. Bermain Data Dengan SQL Server, Bandung.

Raswita.N.P.M.E dan Utama.M.S., 2013. Analisa Pertumbuhan Ekonomi Dan Ketimpangan Pendapatan Antar Kecamatan Di Kabupaten Gianyar, E-Jurnal Ekonomi Pembangunan Universitas Udayana Vol. 2, No. 3.

Razak.A.R., 2011. Economic Growth And Regional Development Disparity In South Sulawesi, Economic Journal Of Emerging Markets, 3(3), 275-287.

Rukmana.I., 2012. Pengaruh Disparitas Pendapatan, Jumlah Penduduk Dan Inflasi Terhadap Pertumbuhan Ekonomi Di Jawa Tengah Tahun 1984-2009, Economics Development Analysis Journal 1 (1).

Sari.P.D.K dan Budhi.M.K.S., 2013. Pertumbuhan Ekonomi Dan Ketimpangan Antar Kecamatan Di Kabupaten Buleleng, E-Jurnal Ekonomi Pembangunan Universitas Udayana Vol. 2, No. 3.

Sokolowich.M.E., 2015. Instituional Perspective of Urban and Regional Economics - Selected Areas of Empirical Application, Journal of Economics and Management Vol. 19(1).

Sudarlan dkk., 2015. Impact Of Mining Sector To Porverty And Income Inquality In Indonesia: A Panel Data Analysis, International Journal Of Scientific \& Technology Research VOLUME 4, ISSUE 06.

Sulistyorini,P., 2010. Pemodelan Visual Dengan Menggunakan UML Dan Rational Rose, Jurnal Teknologi Informasi Dinamik Volume XIV, No.1, 23-29.

Sutarno dan Kuncoro.M., 2003. Pertumbuhan Ekonomi Dan Ketimpangan Antara Kecamatan Di Kabupaten Banyumans, 1993-2003, Jurnal Ekonomi Pembangunan Vol. 8 No. 2, Hal: 97 - 110.

Sutrisno.A., 2012. Analisis Ketimpangan Pendapatan Dan Pengembangan Sektor Unggulan Di Kabupaten Dalam Kawasan BARLINGMASCAKEB Tahun 2007-2010, Economics Development Analysis Journal.

Suwandi.N,. 2015. Economic Inequality among Districts in Keerom, Papua, Indonesia, Journal of Social and Development Sciences Vol. 6, No. 3, pp. 30-34.

Woods.J.G and Lucturer,. 2007. Regional Economic Growth and Income Distribution in California, Journal Of Business and Public Affairs Volume 1. Issue 1.

Yeniwati., 2013. Ketimpangan Ekonomi Antar Provinsi Di Sumatera, Jurnal Kajian Ekonomi, Vol. II, No.03.

Zakaria.S,. 2013. The Impact of Fiscal Deventralization toward Regional Inequalities in Eastern Region of Indonesia, Journal of Economics and Sustainable Development Volume 4, No. 10, 2222-1700.. 